
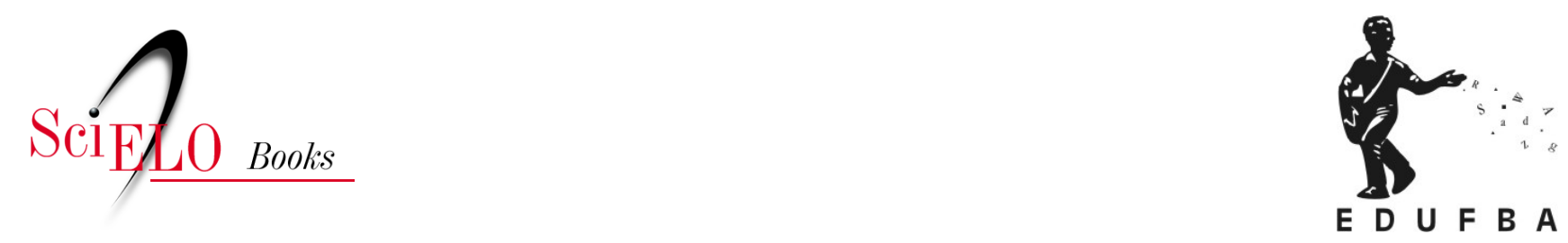

\title{
(Micro)políticas Queer
}

\author{
Fernando Pocahy
}

\section{SciELO Books / SciELO Livros / SciELO Libros}

POCAHY, F. (Micro)políticas Queer. In: MESSEDER, S., CASTRO, M.G., and MOUTINHO, L., orgs. Enlaçando sexualidades: uma tessitura interdisciplinar no reino das sexualidades e das relações de gênero [online]. Salvador: EDUFBA, 2016, pp. 223-233. ISBN: 978-85-232-1866-9.

https://doi.org/10.7476/9788523218669.0012.

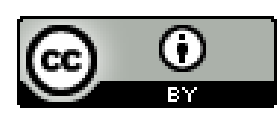

All the contents of this work, except where otherwise noted, is licensed under a Creative Commons Attribution $\underline{4.0 \text { International license. }}$

Todo o conteúdo deste trabalho, exceto quando houver ressalva, é publicado sob a licença Creative Commons Atribição 4.0.

Todo el contenido de esta obra, excepto donde se indique lo contrario, está bajo licencia de la licencia Creative Commons Reconocimento 4.0. 


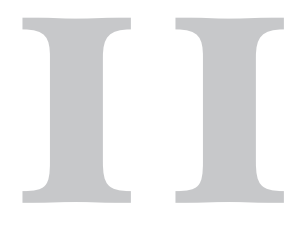

\title{
(Micro)políticas Queer
}

\author{
获 \\ Fernando Pocaby
}

Este é um ensaio de uma cartografia de (micro)políticas queer. Busco com isso problematizar e, pretensiosamente, perturbar o trabalho das milícias epistemológicas das autointituladas ciências da subjetividade - campo em que me movimento, especialmente entre as práticas-saberes da educação e da saúde. A aposta do texto persegue algum tipo de encontro com as fechações/aberturas pós-estruturalistas presentes nas

${ }^{1}$ Comunicação produzida para o IV Enlaçando Sexualidades. Salvador, 26-29 de maio de 2015. Este texto é versão parcial e revisitada de um dos quatro atos (a ato produzido por este autor) que compõem o artigo-manifesto queer "Transconversações queer: sussurros e gemidos lusófonos". Quatro cadelas mirando a(s) Psicologia(s), publicado em 2014 na Revista Periódicus por Fernando Pocahy, Fernando Teixeira Filho, Nuno Santos Carneiro e Wiliam Siqueira Peres. 
insubordinações e nos tráficos de significados acionados na experiência das (micro)políticas queer na pesquisa acadêmica e na produção de subjetividades no campo das políticas educacionais e científicas universitárias.

A escrileitura de mundo que se agencia entre estas poucas páginas não é nada mais do que uma reação alérgica à herança binária do "isto ou aquilo”, à falta (e ao império do falo) como elemento capitalístico-ressentido-dominador, à assunção neuro-farmaco-digital e ao conjunto de interpelações representacionais presentes nas renovadas taxonomias pós-positivistas que marcam a vigilância das subjetividades sob a tutela da heteronormatividade (e seus derivados, como a homotransnormatividade).

Muitas instituições e pessoas entram em pânico diante de qualquer possibilidade de desterritorialização. Encontram-se aflitos diante da perda ou abalo de um suposto "eu" que, a duras penas, tentam (auto)fixar. Outros, sentem-se acuados pelos gladiadores normaloides da moral (não somente aqueles da Igreja Universal, mas todos e todas que se curvam à vontade de poder e exercem suas forças de dominação e terror social - acadêmico, político, estético) e agonizam, como vidas vazias. Atônitos, reagem de forma perversa e raivosa diante movimentos que lhe retiram alguma segurança de individuação. Vociferantes e desejosos de norma, atacam com gritos e panelaços gourmetizados. Suplicam em cânticos religiosos, acadêmicos ou no(s) documento(s) legislativo(s) que Deus ou a ciência os livrem do desmanchamento de suas certezas e de seus privilégios. Pobres vítimas cis-brancas!

Com seus panelaços fazem passar seus fundamentalistas (acadêmicos, religiosos, políticos e até artísticos), assombrando e vigiando devires vadios. Às vezes, por meio de nuances moderadas de patologização das diferenças e alguma concessão, como se fossem donos de algo na vida, toleram-nos a contragosto. Suas práticas molares estão (a)fundadas em desejos de (hetero/homo)norma. Passam dias e vidas ruminando interpretações teológicas ou mesmo científicas - metateóricas - espraiando seu suposto saber, seu saber-poder, suas vontades de poder, no cotidiano das práticas sociais e institucionais, barganhadas em cenas parlamentares ou outros sítios de poder. 
Por vezes, assumindo ares de renovada visitação epistemológica, exibem com um sorriso branco (claro, apegada a um modelo racializador da vida) seus murmúrios de preocupação e suposto entendimento e implicação com as coisas do mundo, oferecendo migalhas sociais aos ditos desviantes e enjeitados da moral familiar burguesa e neoliberal. Monótona e perigosíssima prática dominada pela suposição de um corpo-subjetividade como lugar de verdade. Artífices da própria ficção epistemológica que performativamente intentam realizar materializam-se milicianos da moral e do desejo de morte.

No plano da produção científica colonial, as disciplinas científicas (e apaixonadas pelo poder) se assenhoram dos desejos (para elas, sempre ressentidos e assombrados pelo nome do macho), afastando qualquer conexão com a cultura do presente ou da cultura como plano vivo de insubordinações cotidianas. Percebem quase tudo, mas não se veem em nada do que produzem. Tampouco (se) enxergam. Nada percebem, além do seu apreço pelo cálculo ou pelas inferências e interpretações morais. Seus mapas computadorizados, suas inúmeras combinações e probabilidades, seus enquadramentos/enjaulamentos teóricos e suas interpretações universalizantes não fazem mais do que cintilar a vontade de saber/poder espalhadas por zonas generificadas do corpo ou nas zonas "ainda" desconhecidas. Entre as novas disciplinas e suas apostas teórico-capturantes, arranjos de novas biopolíticas emergem, sugerindo imagens ultra-atormentadas de representações (marcas de poder) de gênero e sexualidade descoladas de qualquer potência de vida. Cienciazinhas/disciplinas enroscadas em performances estatísticas ou significados congelados que não somam mais do que dois e dois diante do (ficcional) social, repetem em coro o cálculo binário da dor: julgam que as pessoas ou são isso ou são aquilo outro. Produto final desta pobre engenharia - performatividades normofásicas/normofálicas.

$\mathrm{Na}$ cama contemporânea de Procusto forja-se um ideal de humano gendrado e atormentado com a sexualidade. A normalização macia desse hospedeiro que, segundo sabe-se da mitologia grega oferecia uma cama na exata medida de seus hóspedes, cerrando-lhes as partes excedentes ou 
espichando as partes faltantes para que coubessem no leito ofertado aos forasteiros, cobre-se (e encobre-se) de um lençol roto de interpelações e traduções normativas da experiência do corpo e, mais amplamente, das derivas e dos devires que inventam a vida. Esquecem-se que tudo é fabricado na cultura. Tudo, no jogo político da agonística de um ideal de humano, é fabricado, ficcionado nas experiências inconfessáveis do devir (se capturam algo, é a sua própria ficção chapada em representações autoconfirmativas de seus delírios de determinação do lugar do outro).

A ciência moral e seus gladiadores epistemonormoides se colocam com o bisturi discursivo da cultura. Não desejam enxergar que a ciência é parte de nossas culturas. Não somos tolxs e sabemos bem que teorias assumem legitimidades em matrizes sexistas, heterossexistas, racistas e, incontestes, produzem a realidade que intentam descrever - performativamente. Estudos e práticas que falam pouco a linguagem que faz corpo, mas fazem o corpo arbitrariamente falar - suplício de confissões, medidas e mesmices interpretativas, cujos refinamentos conceituais não escondem a nova dinâmica biopolítica e neoliberal. Tudo parecendo tão novo. Mas nada menos Moderno.

A heterossexualidade compulsória e a cisgeneridade reinam soberanas no imaginário falo-edipiano de guardiães da norma, gozando (e às vezes só falam deste tal de gozo) de privilégios por conta de suas supostas naturalidade e recompensas por um calendário (re)produtivo do capitalismo neoliberal. Essa ficção biopolítica tece o triste cotidiano das práticas cães de guarda. (ROLNIK, 1997) O rosnado da matilha de guarda conta ainda com a comoção interdisciplinar de um conjunto de subjetividades dobradas a campos de saberes seduzidos e sedutores em planos normativos e moralidades canônicas, estejam elas para as humanas ou para as outras ciências da natureza - cuja arbitrária divisão já revela a atormentada vontade de dividir e de classificar o mundo.

Mas isso tudo não sem recusa, não sem resistência. E é nessa agonística por onde se articulam o que se denominou chamar (micro)políticas queer. Sorte de plano-tática de contestação. Com suas epistemologias de 
mundo profanadoras, inquietas, abusadas, radicalmente promíscuas, suadas, gordas e transbordantes de impaciência diante dos coronéis da nova ordem política nacional (esteja esta nova ordem na academia, na igreja, nos legislativos e outros lugares-práticas de polícia social), multitudes de corpos em fuga fazem a vida pulsar, instaurando outras formas de organização e coletividade apaixonadas pela fluidez e pelo prazer como invenção ético-estético-política da vida contemporaneidade.

E (a meu ver, ou de onde eu alcanço alguma coisa para ver) é na formação em educação e saúde por onde o latido vadio das subjetividades queer torna-se mais barulhento e por onde podemos acompanhar algo mais de sua agonística. Não é atoa que os ataques fundamentalistas tem atingido de forma mais significativa esses dois campos que, nas últimas décadas, assumiram protagonismo na agenda democrática: educação e saúde fortaleceram-se como espaços de ampliação das ferramentas democráticas, hoje ameaçadas.

As inquietações indisciplinares e indisciplinadas agenciadas nos movimentos queer denunciam: a sexualidade está saturada de disciplina. E em aproximação aos latidos discursivos-desconstrucionistas (e desconfiados), o manifesto-reflexão antinormalização queer engorda, explodindo as significas do corpo dócil e útil - ou, mais contemporaneamente, o corpo elástico e biodinâmico.

A alergia social queer age de forma tática e deliberada através do dissenso. Como política epistemológica, como experimentação (re)inventiva do fazer-corpo e ainda como fazer acadêmico em movimentos minoritários, dissidentes, estudiosxs-ativistas queer assumem, como ponto de partida, a proposição de que a pesquisa, a arte, as formas de associativismo e a feitura de nossas práticas sociais são produzidas a partir de jogos de poderes-saberes-prazeres que são vividos sem nenhuma estabilidade, sem nenhuma promessa de vida certa.

Estou convencidx de que pesquisar-produzir conhecimento na experiência queer é uma prática de resistência, efeito da agonística contemporânea dos processos de subjetivação. A produção de potência 
de vida queer encontra-se com a radicalização de uma epistemologia de mundo engendrada no desvio e desde as vidas constituídas no avesso das normas, muitas vezes vidas precárias. Mas a potência de não curvar-se e de (des)dobrar-se epistemologicamente sobre si mesmx e logo abandonar ou se instalar de algum lugar seguro não é vivida sem risco de captura, aliás, este é o jogo, desterritorializar, reterritorializar, desterritorializar... territorializar.

O desatino impertinente e indisciplinado presente nas políticas queer - como algo que não pode ser localizado, mas uma composição epistemológica mutante e contexto-dependente - segue no rastro de tantxs outrxs que se movimentaram em posições dissidentes anticoloniais, antirracistas, antissexistas. Posições interseccionadas com as sexualidades, os corpos e as performances de gêneros minoritárias, emergem não como objetos de investigação, mas como políticas de conhecimento e de tessitura de novas subjetividades. Nessa posição, o corpo-política queer na experiência da formação acadêmica e nas demais práticas sociais entra/aparece como superfície de intensidades e de (des)encontros problematizadores, desumanizando-se das encarnações científicas canônicas, assépticas e morais dos normo-investigadorxs - "toxicômanos de identidade" (ROLNIK, I994) e dos bandos fundamentalistas que disputam zonas de poder.

Entende-se que as políticas queer afirmam-se no cotidiano como (com) posição implicada em combater os fascismos que estabelecem quais vidas valem a pena ser vividas e quais são as que não importam, como nos incita $\mathrm{e}$ excita a pensar Butler (2005). Disto, somos levadxs a pensar que os nossos lugares de pesquisadorxs são marcados por convenções e normas sociais; e que os nossos modos de pesquisar são constituídos por epistemologias "duras" (molares) hierarquizantes ou (moleculares) contestatórias (talvez). Pesquisar/combater/resistir, em uma disposição queer, poderia significar, nesses termos, o agenciamento de uma profusão de estranhamentos sobre as formas de saberes/poderes/prazeres e, ainda, daquilo que é possível conhecer e quem estaria autorizada(o) a produzir conhecimento, como bem já nos apontou Guacira Lopes Louro (2004), pesquisadora que movimentou/ 
atormentou o campo da educação com suas apostas nos estudos queer (a quem faço minhas reverências, não como pessoa sagrada, mas como subjetividade profana, uma orientadora suave e forte, corajosa em seu campo de batalha: a educação).

No rastro destas ideias, acredito que faz sentido pensar em uma produção de conhecimentos entre os lençóis discursivos dos prazeres envolvendo as sexualidades e as performatividades de gênero sem desconsiderar as interseccionalidades com outros marcadores de identidade e de diferença que operam na produção de modos de experimentação de si, movimentando-nos em posições de desigualdades sociais ou de assujeitamento aos microfascismos cotidianos que servem de elemento de localização nas diversas aduanas da vida social. Essas interseccionalidades são formas (discursivas) que organizam os prazeres e os modos de experimentação das sexualidades e não somente a sua opressão/controle/tutela/normalização.

Desenha-se assim o princípio ético nesse plano-potência queer. Entre as formas de conduzir-se a si mesmxs, toma corpo a ideia de recusar parresiasticamente aos bons, limpos e docilizados costumes acadêmicos (como dirá Foucault, a coragem é sempre física). De alguma forma, na insubordinada e inapreensível experiência queer, a desconstrução é sua prática-método, acionada na direção-tática de demover os instituídos das formas hegemônicas de produzir conhecimento, perturbando as epistemologias (con)sagradas e apaixonadas pela "Verdade", pelo poder-saber-poder. Desconstrução que não tem necessariamente a ver com destruição, embora muitos dos embates necessitem de atos potentes e performáticos no sentido de derrubar os muros da apartheid social e cultural agenciado na cena contemporânea, movidos em uma cena cuja dimensão dos perturbados prazeres se oferece também como mais um elemento nessa agonística social do humano contemporâneo.

A forma que muitos dos combates queer assumem sugerem alguma sorte de libertinagem. Mas isto nada teria a ver com liber(t)ação. Trata-se da dissidência científica através de uma postura safada, epistemologicamente apaixonada por um devir-puta. De certa forma busca-se a proliferação da polêmica e do escândalo. E reafirma-se olho no olho que a visualidade da 
pesquisa e do fazer acadêmico é, desde sempre, posicionado na trama dos dispositivos de gênero, classe, sexualidade e de raça. De modo que, diante disto, não se pode jamais desconsiderar a própria experiência corporal do agente pesquisador como alguém também elx assujeitadx por uma produção discursiva que porta as marcas de certa inteligibilidade social, que são recitadas cotidianamente e legitimadas por instituições excludentes, racistas, sexistas e classistas. Assim, como movimento perturbador para a pesquisa, a postura-aposta queer nos lança a desafios relacionados a pensar-fazer (a prática refletida da liberdade, nos termos foucaultianos) como sujeitos engajadxs politicamente nos movimentos de críticas/análises dos processos de autoridade que "a Teoria” confere.

De minha parte, tenho pensado que uma das possibilidades que poderiam se articular a esse modo de operar em pesquisa segue no rastro atormentado da perspectiva genealógica à la Nietzsche, à la Michel Foucault. Como ferramenta conceitual importante para o trabalho de problematização das condições de possibilidade e de emergência dos discursos - que se opõem e/ou associam-se nos jogos de verdade que dão contornos à relação dxs sujeitxs consigo mesmxs, ou seja, no processo de sua (auto)constituição e do conhecimento e dos prazeres-saberes que produzem - trata-se de recusar métodos descritivos que priorizam a constância histórica ou o traço “antropológico" imediato. (FOUCAULT, 2004) Tomaz Tadeu da Silva (2007) faz eco a isso: segundo ele, o mundo estático e morto das coisas e dos significados fixos é um mundo sem disputas.

Por isso as (micro)políticas queer buscam a disputa e dissenso enquanto movimento tático, pois somos todxs restos e rastros desse mundo arregimentado por ilusões normativas, pela suposta segurança da normalidade, ficções de nosso tempo. E como tal, aqui ou ali flertamos com alguma norma, desejosxs de algum conforto e reconhecimento, desejos de alguma sorte de poder ou uma mínima certeza. Nesse sentido, dizer-se/autonomear-se queer já seria, em si mesmo, docilizar o estranho, o bizarro, o ignóbil, o que quer escapar. E talvez eu tenha feito isso em 
algum momento neste texto. Afinal, toda apropriação pode funcionar como forma de sujeição.

Mas se aceitarmos que nenhum texto é sagrado, como já afirmaram tantxs entre aquelxs que operam em perspectivas pós-críticas e pós-humanas, torna-se mesmo arriscado inventar e radicalizar o sentido de "fabricantes" de problemas sobre nosso tempo. Para isso, precisamos de novos e outros modos de pesquisar e intervir. Talvez aqueles modos que tenham a ver com um tipo de curiosidade "vadia" e não com aquela curiosidade perversa que busca assimilar o que convém conhecer, senão aquilo que nos permitiria desfazer, inclusive declinar de ser interpeladxs como queer.

Mais um ataque foucaultiano da matilha queer, anticães de guarda. Queer é também texto. Por isso, não basta Lattes, tem-se que morder, revisitando uma frase atribuída a Gilles Deleuze que, fato ou não, é capaz de produzir sentido: aqui não adianta latir, tem que morder. Mas temos de fazer isso também desde o interior dessas práticas e instituições. É nessa disposição que alguém que se instala em um lugar/fazer acadêmico tem a chance de pensar os problemas de seu tempo, a partir das experiências desmoralizadas e desmontadas de suas próprias subjetividades - bricoladas em e desde seu tempo, em e desde sua cultura - de suas próprias instituições.

Como provocação final, cabe ponderar que um dos efeitos queer na cena acadêmica também nos remete a um plano de pesquisa(in[ter]venções) como modo problematização que escarnifica os regimes discursivos que se organizam a partir da gestão da vida, historicizando o presente em suas formas de controle, deciframento, incitação para o corpo dócil e útil - na ordem e na organização espacial e institucional das subjetividades. Pesquisar-intervir-viver nas fronteiras - lá pelas brechas, entremargens, diante e com o que e quem escapa/foge - nos permite deslocar os gêneros e as sexualidades dos lugares centrais de chaves de acesso à verdade dxs sujeitxs, no mesmo instante em que podemos, assim, desestabilizar as pretensas naturalidade e evidência da heterossexualidade (e até mesmo da homossexualidade, em sua paixão pela origem, identidade ou essência) 
e os desesperados movimentos normalizadores. Talvez, trate-se ainda de induzir políticas diante de efeitos de verdades - nos quais se fabrica qualquer coisa que ainda não existe, afirmou Foucault (200I).

Ao reafirmar o caráter fabricado/ficcional e político de uma pesquisa (in[ter] venção) e dos sujeitos que fazem pesquisa, questionando o lugar de quem pode ou não dizer ou conhecer algo, estamos contestando as formas autorizadas do conhecer e de quem está autorizadx a conhecer. As cadelas de Nietzsche já nos morderam profundamente e propagaram entre nós a raiva epistemológica que faz alguns de nós vidas (vadias) abjetas na academia. O latido reverbera: toda vontade de classificação e de interpretação objetivadora é uma vontade de poder.

A pesquisa e a in[ter] venção podem ser planos de criações culturais. A pesquisa-fazer acadêmico como agente do devir, como plano de invenção de movimentos éticos, estéticos e políticos, pensando-vivenciando o corpo como uma força possível para multitudes de prazeres e de sentidos nômades, inclassificáveis. Arrisco sugerir que nos caberia em uma reverberação queer um trabalho mais indisciplinado sobre nós mesmxs (mas não menos rigoroso e vigoroso), começando por não desejarmos saber quem somos, para não cairmos na armadilha de permanecer xs mesmxs, do mesmo modo como já nos advertiu Foucault (2004, p. 20): "vários, como eu sem dúvida, escrevem para não ter mais um rosto. Não me pergunte quem sou e não me diga para permanecer o mesmo: é uma moral de estado civil; ela rege nossos papéis. Que ela nos deixe livre quando se trata de escrever".

No avesso dos bons costumes acadêmicos, uma in(ter)venção: movimentarmo-nos em cartografias-práticas ético-estético-políticas, a começar por uma análise sobre nossas próprias subjetividades produzidas no campo minado da(s) episteme(s) de nosso(s) tempo(s)-espaço(s)-lugar(es). Qualquer definição de um impacto queer sobre estas práticas-campo seria um ato normo-colonizador. Não se deseja a ontologia do eu ou de um modo de fazer que seria melhor que outro, mas estamos mais interessadxs naquilo que nos tornou um eu classificável, governável, "supostamente" 
real e supostamente incontestável em sua materialidade física. Não se reivindica no plano queer algum lugar ou status na hierarquia dos valores acadêmicos diante do uso das teorias e conceitos perturbadores. Flertar como os modos de vida-pensar queer, com as suas micropolíticas, convida a que revisitemos nossos próprios tormentos e os riscos que derivam de alguma paixão pelo poder em nossas recaídas normapatas.

Não creio que se esteja desejosx de ser ou se reconhecer queer. Estamos em busca de qualquer coisas ou nome que nos faça escapar - entrada-saídamovimento de fazer fugir a partir de um plano de curiosidades que ousa lamber, latir e até morder, mas sem nome e sem pedir licença para existir.

\section{Referências}

BUTLER, J. Humain, inbumain. Le travail critique des normes. Entretiens. Paris: Éditions Amsterdam, 2005.

FOUCAULT, M. A arqueologia do saber. Rio de Janeiro: Forense Universitária, 2004.

FOUCAULT, M. Les rapports de pouvoir passent à l'intérieur des corps. In: FOUCAULT, M. Dits et écrits II, 1976-1988. Paris: Gallimard, 200I. p. 228-236.

LOURO, G. L. Um corpo estranbo. Ensaios sobre sexualidade e teoria queer. Belo Horizonte: Autêntica, 2004.

ROLNIK, S. Toxicômanos de identidade. In: LINS, D. Cultura e subjetividade. Saberes Nômades. Campinas: Papirus, 1997. p.19-24.

ROLNIK, S. Cidadania e alteridade: o psicólogo, o homem da ética e a reinvenção da democracia. In: SPINK, M. J. (Org.). A cidadania em construção uma reflexão transdisciplinar. São Paulo: Cortez, 1994, pp. 157-176.

SILVA, T. T. A produção social da identidade e da diferença. In: SILVA, T. T. (Org.). Identidade e diferença. A perspectiva dos estudos culturais. Petrópolis, RJ: Vozes, 2007. p. 73-IO2. 